Damen, N.L., Baines, R., Wagner, C., Langelaan, M. Medication-related adverse events during hospitalization: a retrospective patient record review study in the Netherlands. British Journal of Clinical Pharmacology: 2016

\begin{tabular}{|l|l|}
\hline $\begin{array}{l}\text { Postprint } \\
\text { Version }\end{array}$ & 1.0 \\
\hline Journal website & http://dx.doi.org/10.1002/pds.4037 \\
\hline Pubmed link & http://www.ncbi.nlm.nih.gov/pubmed/27193415 \\
\hline DOI & $10.1002 /$ pds.4037 \\
\hline
\end{tabular}

This is a NIVEL certified Post Print, more info at http://www.nivel.eu

\title{
Medication-related adverse events during hospitalization: a retrospective patient record review study in The Netherlands
}

\author{
NiKKI L. DAMEN ${ }^{1, *}$, ReBeCCA BAINES $^{1}$, CORDULA WAGNER ${ }^{1,2}$ AND MAAIKE LANGELAAN $^{1}$ \\ ${ }^{1}$ Netherlands Institute for Health Services Research (NIVEL), Utrecht, The Netherlands \\ ${ }^{2}$ VU University Medical Center/EMGO ${ }^{+}$Institute, Amsterdam, The Netherlands
}

\begin{abstract}
Purpose: Medication-related adverse events (MRAEs) are an important priority for patient safety. Results from Dutch AE studies showed that-despite various improvement initiatives - the incidence of preventable MRAEs did not decline. The aim of this study is to describe the characteristics of MRAEs during hospitalizations using national patient data from records of patients admitted to Dutch hospitals in 2008 and 2011/2012.

Methods: Trained nurses and physicians reviewed the randomly selected records of 8071 patients admitted to one of 20 hospitals in 2008 or 2011/2012 during a two-stage review process. Patient and admission characteristics were collected. After identification of a MRAE, physicians determined their potential preventability, drug type, related prescribing factors, and potential consequences.

Results: The physicians identified 928 adverse events (AEs) in 857 admissions, of which $218(15.2 \%)$ were medication-related. They judged $55(18.4 \%)$ of these as preventable. Preventability of MRAEs was high in anticoagulant treatment $(42.5 \%)$. Haematoma $(39.0 \%)$ and intra-cerebral haemorrhage $(25.5 \%)$ were common types of anticoagulant-related AEs. Anticoagulantrelated AEs were often related to dosage factors (46.9\%) and often resulted in an intervention (80.2\%), of which $40.2 \%$ was judged as preventable.

Conclusions: This study provided detailed information on MRAEs during hospital admissions in The Netherlands. A substantial proportion of AEs was medication-related (15.2\%), of which $18.4 \%$ was judged to be preventable. As preventability in MRAEs was especially high in anticoagulant treatment $(42.5 \%)$, those medications are a threat to patient safety. Future research and new safety programs should focus on prevention of AEs related to this medication group.
\end{abstract}


Damen, N.L., Baines, R., Wagner, C., Langelaan, M. Medication-related adverse events during hospitalization: a retrospective patient record review study in the Netherlands. British Journal of Clinical Pharmacology: 2016

\section{INTRODUCTION}

Patient safety continues to be a major challenge and a high priority in hospitals worldwide. Healthcare-related adverse events (AEs) are common and can be defined as unintended injuries that result in temporary or permanent disability, death, or prolonged hospitalization, caused by healthcare management rather than patients' underlying disease.[1-4]

Medication-related adverse events (MRAEs) occur as a consequence of medication errors or adverse drug reactions and are one of the most common types of healthcarerelated AEs.[4-6] In The Netherlands, the first national AE study took place in 2004, in which the extent and nature of AEs and their preventability were evaluated in 21 Dutch hospitals.[7] The results from this study indicated that MRAEs comprise around $15 \%$ of all AEs, with almost $30 \%$ of them being preventable.[8-10] In addition, MRAEs were associated with considerable longer hospital stays and higher healthcare costs, [9] imposing a high burden on patients, caregivers, and the healthcare system. These results were in line with findings from other AE studies[1114] and also confirmed in systematic reviews and meta-analyses.[5, 6]

Over the last years, the prevention of AEs has become an important priority for patient safety in The Netherlands. In 2008, the national program 'Prevent Harm, Work Safely' was launched. The overall goal of this safety program was to reduce the number of preventable AEs in Dutch hospitals by 50\% through the implementation of a Safety Management System in all hospitals and through improvement modules on 10 clinical themes, including medication processes such as medication reconciliation and high-risk medication.[15]

To keep track of changes in patient safety on a national level, a second and third measurement of the national AE study was conducted in 2008 and 2011/2012. In recent publications, general trends in AEs over time and main categories of preventable AEs have been assessed.[16, 17] These studies showed that-despite various safety improvement initiatives such as the safety program-the incidence of preventable MRAEs did not decline over the years. Hence, the aim of the current study is to describe the characteristics of (potential preventable) MRAEs during hospitalizations, using national patient data from records of patients admitted to Dutch hospitals in 2008 and 2011/2012. This information could contribute to the design of future medication safety initiatives.

\section{METHODS}

\section{Study design and population}

We used the data from two of our previous AE studies, $[16,17]$ in which patient records of hospital admissions in 2008 and 2011/2012 were assessed. Review of these admissions records took place in 2009/2010 and 2012/2013, respectively. In both studies, the same 20 hospitals of the in total 93 Dutch hospitals were included. The hospital samples were both stratified by hospital type: university, tertiary teaching, and general hospitals. Within these strata, hospitals were randomly selected, and a proper representation of urban and rural settings in the sample was verified. Per hospital, for each measurement year, about 200 patient admissions were randomly selected: half of these consisted of admissions of patients discharged alive from the hospital after a stay of at least $24 \mathrm{~h}$. The other half consisted of inpatient 
Damen, N.L., Baines, R., Wagner, C., Langelaan, M. Medication-related adverse events during hospitalization: a retrospective patient record review study in the Netherlands. British Journal of Clinical Pharmacology: 2016

deaths regardless of the length of hospital stay. In both studies, only one admission per patient was included. As was also common in other AE studies, records from patients admitted to the psychiatry or obstetrics department, and records of children younger than 1 year of age were excluded. Detailed information on the design of the studies was published previously.[7, 17] Both study protocols were approved a priori by the medical ethics committee of the VU University Medical Center, Amsterdam, The Netherlands.

\section{Patient record review}

Trained external nurses and external physicians reviewed the nursing and medical records of included admissions. The method of determining AEs, which was comparable to those of other international studies $[18,19]$ and based on the Canadian AE study,[1] comprised two phases: first, a nurse screened the records by using triggers indicating potential AEs. In the second phase, a physician further reviewed admissions positive for at least one trigger. These physicians belonged to the specialty surgery, internal medicine, or neurology, and AE reviews were assigned based on their specialty. If needed, they could consult with specialties other than their own. Patient records of the index-hospital admission were reviewed, as were the patient records of patient admissions a year before and after the index-admission. Presence of AEs was determined by the physicians based on a standardized procedure.

An AE was defined by three criteria:

1. An unintended physical or mental injury;

2. The injury resulted in prolongation of hospital stay, temporary or permanent disability or death;

3. The injury was caused by healthcare management rather than the patient's underlying disease.

To determine whether the injury was caused by healthcare management or the disease process, a six-point Likert scale was used:

1. (Virtually) no evidence of management causation;

2. Slight to modest evidence of management causation;

3. Management causation not likely $(<50 / 50$, but borderline);

4. Management causation more likely ( $>50 / 50$, but borderline);

5. Moderate to strong evidence of management causation;

6. (Virtually) certain evidence of management causation.

The cause of an AE was counted as caused by healthcare if the score was 4-6. If an $\mathrm{AE}$ was identified, questions about the clinical process during which the $\mathrm{AE}$ occurred were asked. Physicians were able to choose from the following clinical processes: diagnostics, surgery, drug, medical procedure, other clinical management, discharge, and others. All AEs in which a drug was chosen to be the main clinical process during which the AE had occurred were marked as MRAEs.

A MRAE was considered to be preventable when the care given fell below the current level of expected performance of practitioners or systems. In accordance with 
Damen, N.L., Baines, R., Wagner, C., Langelaan, M. Medication-related adverse events during hospitalization: a retrospective patient record review study in the Netherlands. British Journal of Clinical Pharmacology: 2016

our previous studies, $[7,9,16]$ preventability was assessed on the following six-point Likert scale:

1. Almost no evidence of preventability;

2. Slight to modest evidence of preventability;

3. Modest preventability $(<50 / 50$, but borderline);

4. Modest to strong evidence of preventability ( $>50 / 50$, but borderline);

5. Strong evidence of preventability;

6. Almost certain evidence of preventability.

A score of 4-6 indicated that the reviewer regarded the MRAE as having a greater than $50 \%$ chance of being potentially preventable.

To add more structure to the implicit review process, the causation and preventability scores were each preceded by 13 questions to facilitate the final reviewers' judgment. In addition, physicians were trained in assessing the causation and preventability prior to reviewing patient admissions, and frequent reflection meetings were organized to uphold a high quality of the review process.

After identification of a MRAE, the physician reviewers determined among others drug type, related prescribing factors, and potential consequences associated with the MRAE.[1] As for the timing of MRAEs, MRAEs that occurred during the patient's index-hospital admission and were detected during either the index-admission ( $n=147)$ or subsequent admissions over the following 12-month period $(n=13)$ were counted. Also counted were MRAEs related to patient admissions in the same hospital within the 12 months preceding the index-admission but which were not detected until the index-admission $(n=58)$. Exceptions were made for MRAEs related to hair loss as a result of cytostatic treatment and neutropenia without fever, as these were common side effects of cancer chemotherapy, and therefore, not counted as AEs in this study.

\section{Statistical methods}

\section{Weighting procedure}

In accordance with our previous studies, $[8,9,16]$ during analyses, all proportions were corrected for the oversampling of deceased patients and university hospitals. In our sample, $50 \%$ of the patients were inpatient deaths, whereas in reality, this is $3 \%$. In the results, we weighted our $50 \%$ back to the actual $3 \%$. We followed the same procedure for the distribution of hospital types: In our sample, $20 \%$ of the hospitals were university hospitals, whereas in reality, this is $10 \%$. Therefore, in the results, we weighted our $20 \%$ back to the actual $10 \%$. After weighting for this sample frame, the total study sample — that is, both discharged and deceased patients — was representative of the total Dutch population of hospitalized patients. Detailed information on the weighting procedure was published previously.[7] As a consequence of the weighting process, proportions were not directly comparable to the accompanying crude numbers.

\section{Conducted analyses}

Summary and descriptive statistics for patient and admission characteristics were calculated for all reviewed patients and for all patients who were assessed to have experienced an MRAE. SPSS complex samples were used to calculate weighted rates 
Damen, N.L., Baines, R., Wagner, C., Langelaan, M. Medication-related adverse events during hospitalization: a retrospective patient record review study in the Netherlands. British Journal of Clinical Pharmacology: 2016

of patients who had experienced at least one MRAE during the admission and their preventability (referred to as 'MRAEs - admission level' in the accompanying tables). As it was possible for patients to experience more than one MRAE during a hospital admission, we also assessed the total number of MRAEs and preventable MRAEs (referred to as 'MRAEs - adverse event level' in the accompanying tables). We further analysed medication type. For the drug type most frequently related to a preventable MRAE, we further analysed possible related prescribing factors as well as consequences. All statistical analyses were performed in SPSS 20.0 and STATA 13.

\section{RESULTS}

In total, records of 8071 patient admissions were included in the study, of which 4023 of 2008 and 4048 of 2011/2012. Patient and hospital characteristics of the study sample are described in Table 1.

\section{[TABLE 1]}

\section{Medication-related adverse events}

The hospital admissions were assessed for the presence of AEs and MRAEs and their preventability. In the second stage, the physicians identified 928 AEs in 857 admissions, of which $218(15.2 \%)$ in 204 admissions were medication-related. They judged 55 (18.4\%) of these MRAEs in 53 admissions as preventable. MRAEs often occurred in patients aged 66-79 years. The preventability of MRAEs was high in patients who died in-hospital, urgently admitted patients, patients admitted to a urology or neurology department, and patients admitted to tertiary teaching hospitals (Table 2).

\section{[TABLE 2]}

Table 3 shows that the majority of MRAEs were adverse drug reactions related to cancer chemotherapy $(n=58,22.0 \%)$, anticoagulant treatment $(n=43,17.1 \%)$, and antibiotics $(n=22,13.6 \%)$. Preventability in MRAEs was especially high in anticoagulant treatment $(n=17,42.5 \%)$ and insulin/oral diabetics $(n=7,34.8 \%)$. MRAEs related to chemotherapy were seldom considered preventable: $0.7 \%(n=3)$ of all chemotherapy-related MRAEs.

\section{[TABLE 3]}

\section{Anticoagulant-related adverse events}

As MRAEs related to anticoagulant treatment were common and often preventable, we further analysed this type of medication. Although preventability in insulin/oral diabetic-related MRAEs was also found to be high, they only comprised 5.0\% $(n=12)$ of total MRAEs (Table 3$)$. Therefore, because of power constraints, we did not perform further analyses on this medication type.

Most anticoagulant-related AEs were related to coumarins $(n=24,55.8 \%)$ and heparins $(n=13,30.2 \%)$ (results not shown in table). Although numbers were small, most of the anticoagulant-related AEs were among patients of 66 years or older and 
Damen, N.L., Baines, R., Wagner, C., Langelaan, M. Medication-related adverse events during hospitalization: a retrospective patient record review study in the Netherlands. British Journal of Clinical Pharmacology: 2016

in patients urgently admitted. The preventability of anticoagulant-related AEs was high in urgently admitted patients and patients admitted to tertiary teaching hospitals (Table 4).

\section{[TABLE 4]}

Haematoma ( $n=5,39.0 \%)$, intra-cerebral haemorrhage $(n=8,25.5 \%)$, and gastrointestinal bleeding $(n=9,12.6 \%)$ were common types of anticoagulant-related AEs. Anticoagulant-related AEs were often related to dosage factors $(n=14,46.9 \%)$, of which $66.2 \%(n=7)$ was judged as preventable. Although therapeutic factors were less often related to anticoagulant-related AEs, their preventability was high $(n=4$, 90.6\%). Anticoagulant-related AEs often resulted in an intervention $(n=26,80.2 \%)$, of which $40.2 \%(n=10)$ was judged as preventable. In $18.9 \%(n=2)$, anticoagulantrelated AEs resulted in readmission (Table 5).

\section{[TABLE 5]}

\section{DisCUSSION}

In the current study, a substantial proportion of all healthcare-related AEs were medication-related $(n=218,15.2 \%)$. Of all 218 identified MRAEs, $55(18.4 \%)$ were deemed to be preventable. Preventability of MRAEs was especially high in anticoagulant treatment $(n=17,42.5 \%)$. Haematoma $(n=5,39.0 \%)$ and intracerebral haemorrhage $(n=8,25.5 \%)$ were common types of anticoagulant-related AEs. Anticoagulant-related AEs were often related to dosage factors $(n=14,46.9 \%)$, and they often resulted in an intervention $(n=26,80.2 \%)$, of which $40.2 \%(n=10)$ was judged as preventable.

The results of this study corroborate the findings of previous studies, demonstrating that MRAEs were responsible for $12-37 \%$ of all AEs, $[2,4,9,11-14,17]$ which was also confirmed in systematic reviews and meta-analyses.[5, 6, 20-22] In these earlier studies, $30-50 \%$ of MRAEs was judged to be preventable, whereas in our study, this number was considerably lower (18.4\%). The finding that anticoagulant treatment accounted for a substantial proportion of preventable MRAEs was also in line with previous research.[11, 13, 23-25] As compared with the results of the first measurement of the national AE study,[9] no visible differences were found in the occurrence of anticoagulant-related MRAEs (18.0\% in $2004 \mathrm{vs.} 17.1 \%$ in this study, respectively), but their preventability slightly decreased from $54.0 \%$ in 2004 to $42.5 \%$ in our study.

Over the past decades, several interventions have been developed to reduce MRAEs and improve medication safety. In The Netherlands, the national program 'Prevent Harm, Work Safely' was launched in 2008 and aimed to reduce the number of preventable AEs in Dutch hospitals by $50 \%$. The program included two improvement modules on medication processes: reducing events that involve high-risk medication and reducing medication errors on admission and discharge.[15] Baines et al. (2015)[16] concluded that during the safety program, no visible improvements in medication safety were established. MRAEs are therefore still a threat to patient safety, and our results indicate that especially on certain high-risk medications, such as anticoagulant treatment, many preventable MRAEs still occur. 
Damen, N.L., Baines, R., Wagner, C., Langelaan, M. Medication-related adverse events during hospitalization: a retrospective patient record review study in the Netherlands. British Journal of Clinical Pharmacology: 2016

Other intervention methods and tools to prevent MRAEs have also been proposed. The most commonly implemented interventions are 'computerized physician order entry systems (CPOEs)', a form of patient management software allowing healthcare providers to electronically enter patient treatment instructions.[26, 27] While CPOE systems are well implemented in most hospitals, a considerable amount of MRAEs was still reported, and CPOE systems introduced new types MRAE as well.[28, 29] Clinical pharmacy interventions have also been investigated, with a hospital pharmacist interacting and advising the healthcare team.[30, 31] Although these interventions contributed to the reduction of (preventable) MRAEs, most of them are costly and time consuming and difficult to provide continuously.[31] Recent research showed that evidence-based drug rules seem promising in preventing MRAEs, but their clinical efficacy is yet to be tested.[32]

Although in the current study, anticoagulant-related AEs were the most common types of preventable MRAEs, none of the aforementioned interventions specifically targeted this medication group. Anticoagulant care is considered complex, and potential risks of bleeding and thrombosis should always be taken into account. In addition, various healthcare professionals are involved in the treatment of patients, including medical specialists, pharmacists, general practitioners, dentists, and the anticoagulation services. These different healthcare providers need to collectively coordinate anticoagulant care. It was previously argued that suboptimal communication and coordination within this 'chain' of healthcare providers is common and associated with adverse patient outcomes.[33] In The Netherlands, several guidelines have been developed addressing these integrated care problems, but one of our recent studies showed that adherence to these guidelines is still trivial.[34] Future research is needed to further examine the complex nature of MRAEs, hereby focussing on hospital-related factors as well as suboptimal integrated care. This knowledge could contribute to the design of future medication safety initiatives, which should especially target the areas with the highest risk of preventable MRAEs, such as anticoagulant treatment.

\section{Strengths and limitations}

One of the strengths of the current study is that we reviewed 8071 patient records over two periods in time based on an international method for standardized assessment method of patient admissions. Although assessing patient records on AEs is a difficult process, retrospective chart studies currently offer the best method available to assess their incidence and are considered as the 'golden standard'.[35] This more implicit method also allows us to focus on a broad range of MRAEs instead of an explicit range of MRAEs and gives a good insight in the general state of medication safety in hospitals.

Retrospective review studies also have disadvantages. The incidence of preventable MRAEs may be underestimated because not all information is available or written down in the patient records.[36] However, due to hindsight bias the incidence of MRAEs may have been overestimated.[37] As knowing the outcome of an admission may influence the judgement of the causality and preventability of MRAEs. We found that anticoagulants still account for a large proportion of the total amount of preventable MRAEs. Unfortunately, we did not register the use of anticoagulants and other medications for all included patients. Therefore, a numerator was not available, and the incidence of anticoagulant-related AEs could not be calculated. 
Damen, N.L., Baines, R., Wagner, C., Langelaan, M. Medication-related adverse events during hospitalization: a retrospective patient record review study in the Netherlands. British Journal of Clinical Pharmacology: 2016

\section{CONCLUSION}

The current study provided detailed information on MRAEs during hospital admissions in The Netherlands. A substantial proportion of AEs was medicationrelated $(n=218,15.2 \%)$, of which $18.4 \%(n=55)$ was judged to be preventable. As preventability in MRAEs was especially high in anticoagulant treatment $(n=17$, $42.5 \%$ ), those medications are a threat to patient safety. It is therefore recommended that future research and new safety programs focus on the prevention of AEs related to this high-risk medication group.

\section{Conflict of Interest}

The authors declare no conflict of interest.

Key Points:

- Medication-related adverse events (MRAEs) are common types of healthcare-related adverse events (AEs) and an important priority for patient safety.

- Recent AE studies indicated that their incidence did not decline over the past years despite various improvement initiatives.

- Characterization of MRAEs in hospitals is lacking.

- The results of this study show that preventability in MRAEs is especially high in anticoagulant treatment.

- Anticoagulant-related AEs often result in an intervention, of which a substantial proportion is preventable.

- Future research and new safety programs should focus on the prevention of anticoagulant-related AEs, as they are a threat to patient safety.

\section{Competing Interests}

All authors have completed the Unified Competing Interest form at http://www.icmje.org/coi_disclosure.pdf (available on request from the corresponding author) and declare: no support from any organization for the submitted work, no financial relationships with any organizations that might have an interest in the submitted work in the previous 3 years, and no other relationships or activities that could appear to have influenced the submitted work.

\section{Acknowledgements}

This research was supported by the Dutch Ministry of Health, Welfare, and Sport. 
Damen, N.L., Baines, R., Wagner, C., Langelaan, M. Medication-related adverse events during hospitalization: a retrospective patient record review study in the Netherlands. British Journal of Clinical Pharmacology: 2016

\section{REFERENCES}

1 Baker GR, Norton PG, Flintoft V, et al. The Canadian Adverse Events Study: the incidence of adverse events among hospital patients in Canada. Can Med Assoc J 2004; 170: 16781686.

2 Davis P, Lay-Yee R, Briant R, et al. Adverse events in New Zealand public hospitals I: occurrence and impact. New Zeal Med J 2002; 115: U271.

3 Wilson RM, Runciman WB, Gibberd RW, et al. The quality in Australian Health Care Study. Med J Australia 1995; 163: 458-471.

4 Bates DW, Cullen DJ, Laird N, et al. Incidence of adverse drug events and potential adverse drug events: implications for prevention. JAMA 1995; 274: 29-34. doi:10.1001/jama.1995.03530010043033.

5 Hakkarainen KM, Hedna K, Petzold M, Hägg S. Percentage of patients with preventable adverse drug reactions and preventability of adverse drug reactions - a meta-analysis. PLoS One 2012; 7 e33236. doi:10.1371/journal.pone.0033236.

6 de Vries EN, Ramrattan MA, Smorenburg SM, Gouma DJ, Boermeester MA. The incidence and nature of in-hospital adverse events: a systematic review. Qual Saf Health Care 2008; 17: 216-223. doi:10.1136/qshc.2007.023622.

7 Zegers M, de Bruijne MC, Wagner C, et al. Design of a retrospective patient record study on the occurrence of adverse events among patients in Dutch hospitals. BMC Health Serv Res 2007; 7: 27. doi:10.1186/1472-6963-7-27.

8 Zegers M, de Bruijne MC, Wagner C, et al. Adverse events and potentially preventable deaths in Dutch hospitals: results of a retrospective patient record review study. Qual Saf Health Care 2009; 18: 297-302. doi:10.1136/qshc.2007.025924.

9 Hoonhout LH, de Bruijne MC, Wagner C, et al. Nature, occurrence and consequences of medication-related adverse events during hospitalization: a retrospective chart review in the Netherlands. Drug Saf 2010; 33: 853-864. doi:10.2165/11536800-000000000-00000.

10 De Bruijne MC, Zegers M, Hoonhout LHF, Wagner C. Potentially preventable adverse events in Dutch Hospitals: patient record review of hospital admissions in 2004. EMGO Institute for Health and Care Research (EMGO+): Amsterdam, 2007.

11 Hakkarainen KM, Gyllensten H, Jönsson AK, et al. Prevalence, nature and potential preventability of adverse drug events - a population-based medical record study of 4970 adults. Br J Clin Pharmacol 2014; 78: 170-183. doi:10.1111/bcp.12314.

12 Davis P, Lay-Yee R, Briant R, et al. Adverse events in New Zealand public hospitals II: preventability and clinical context. New Zeal Med J 2003; 116: U624.

13 Leendertse AJ, Egberts AG, Stoker LJ, van den Bemt PA, Group HS. Frequency of and risk factors for preventable medication-related hospital admissions in the Netherlands. Arch Int Med 2008; 168: 1890-1896. doi:10.1001/archinternmed.2008.3.

14 Sousa P, Uva AS, Serranheira F, Nunes C, Leite ES. Estimating the incidence of adverse events in Portuguese hospitals: a contribution to improving quality and patient safety. BMC Health Serv Res 2014; 14: 311. doi:10.1186/1472-6963-14-311.

15 VMS. VMS Safety Program. 2009; http://www.vmszorg.nl

16 Baines R, Langelaan M, de Bruijne M, Spreeuwenberg P, Wagner C. How effective are patient safety initiatives? A retrospective patient record review study of changes to patient safety over time. BMJ Qual Saf 2015. doi:10.1136/bmjqs-2014-003702.

17 Baines RJ, Langelaan M, de Bruijne MC, et al. Changes in adverse event rates in hospitals over time: a longitudinal retrospective patient record review study. BMJ Qual Saf 2013; 22: 290-298. doi:10.1136/bmjqs-2012-001126.

18 Brennan TA, Leape LL, Laird NM, et al. Incidence of adverse events and negligence in hospitalized patients. N Engl J Med 1991; 324: 370-376. doi:10.1056/NEJM199102073240604.

19 Vincent C, Neale G, Woloshynowych M. Adverse events in British hospitals: preliminary retrospective record review. Br Med J 2001; 322: 517-519. doi:10.1136/bmj.322.7285.517.

20 Beijer HJM, de Blaey CJ. Hospitalisations caused by adverse drug reactions (ADR): a meta-analysis of observational studies. Pharm World Sci 2002; 24: 46-54.

doi:10.1023/A:1015570104121. 
Damen, N.L., Baines, R., Wagner, C., Langelaan, M. Medication-related adverse events during hospitalization: a retrospective patient record review study in the Netherlands. British Journal of Clinical Pharmacology: 2016

21 Lazarou J, Pomeranz BH, Corey PN. Incidence of adverse drug reactions in hospitalized patients: a meta-analysis of prospective studies. JAMA 1998; 279: 1200-1205. doi:10.1001/jama.279.15.1200.

22 Cano FG, Rozenfeld S. Adverse drug events in hospitals: a systematic review. Cad Saude Publica 2009; 25(Suppl 3): S360-S372.

23 Ruiter R, Visser LE, Rodenburg EM, et al. Adverse drug reaction-related hospitalizations in persons aged 55 years and over: a population-based study in the Netherlands. Drug Aging 2012; 29: 225-232. doi:10.2165/11599430-000000000-00000.

24 van der Hooft CS, Dieleman JP, Siemes C, et al. Adverse drug reaction-related hospitalisations: a population-based cohort study. Pharmacoepidemiol Drug Saf 2008; 17 : 365-371. doi:10.1002/pds.1565.

25 Jennings HR, Miller EC, Williams TS, Tichenor SS, Woods EA. Reducing anticoagulant medication adverse vents and avoidable patient harm. Joint Comm J Qual Patient Saf 2008; 34: 196-200.

26 Koppel R, Metlay JP, Cohen A, et al. Role of computerized physician order entry systems in facilitating medication errors. JAMA 2005; 293: 1197-1203. doi:10.1001/jama.293.10.1197.

27 Bates DW, Leape LL, Cullen DJ, et al. Effect of computerized physician order entry and a team intervention on prevention of serious medication errors. JAMA 1998; 280: 13111316. doi:10.1001/jama.280.15.1311.

28 Schiff GD, Amato MG, Eguale T, et al. Computerised physician order entry-related medication errors: analysis of reported errors and vulnerability testing of current systems. BMJ Qual Saf 2015; 24: 264-271. doi:10.1136/bmjqs-2014-003555.

29 Strom BL, Schinnar R, Aberra F, et al. Unintended effects of a computerized physician order entry nearly hard-stop alert to prevent a drug interaction: a randomized controlled trial. Arch Int Med 2010; 170: 1578-1583. doi:10.1001/archinternmed.2010.324.

30 Kucukarslan SN, Peters M, Mlynarek M, Nafziger DA. Pharmacists on rounding teams reduce preventable adverse drug events in hospital general medicine units. Arch Intern Med 2003; 163: 2014-2018. doi:10.1001/archinte.163.17.2014.

31 Kaboli PJ, Hoth AB, McClimon BJ, Schnipper JL. Clinical pharmacists and inpatient medical care: a systematic review. Arch Intern Med 2006; 166: 955-964. doi:10.1001/archinte.166.9.955.

32 Ramrattan MA, Boeker EB, Ram K, et al. Evidence based development of bedside clinical drug rules for surgical patients. Int J Clin Pharm 2014; 36: 581-588. doi:10.1007/s11096014-9941-x.

33 The Dutch Health Care Inspectorate. Anticoagulant care chain not sufficiently sound. The Hague, 2010.

34 Damen N, Damen P, van Dijk L, de Bakker D, Wagner C. Implementation of the National Standard Anticoagulation Chain (V2.0): current state of affairs. NIVEL: Utrecht, 2015.

35 Shojania KG, Marang-van de Mheen PJ. Temporal trends in patient safety in the Netherlands: reductions in preventable adverse events or the end of adverse events as a useful metric? BMJ Qual Saf 2015. doi:10.1136/bmjqs-2015-004461.

36 Zegers M, de Bruijne MC, Spreeuwenberg $P$, et al. Quality of patient record keeping: an indicator of the quality of care? BMJ Qual Saf 2011; 20: 314-318. doi:10.1136/bmjqs.2009.038976.

37 Henriksen K, Kaplan H. Hindsight bias, outcome knowledge and adaptive learning. Qual Saf Health Care 2003; 12(Suppl 2): ii46-ii50. 
Damen, N.L., Baines, R., Wagner, C., Langelaan, M. Medication-related adverse events during hospitalization: a retrospective patient record review study in the Netherlands. British Journal of Clinical Pharmacology: 2016

\section{TABLES}

Table 1. Patient and hospital characteristics of the study sample

\begin{tabular}{|c|c|c|c|}
\hline & \multicolumn{3}{|c|}{ Total population } \\
\hline & $n$ & Unweighted $\%$ & Weighted $\% *$ \\
\hline Inpatient admissions & 8071 & & \\
\hline \multicolumn{4}{|l|}{ Hospital admission year } \\
\hline 2008 & 4023 & 49.9 & 49.8 \\
\hline $2011 / 2012$ & 4048 & 50.1 & 50.2 \\
\hline $\begin{array}{l}\text { Age in years, mean } \\
\text { (median/SD) }\end{array}$ & & & $60.2(64.0 / 20.8)$ \\
\hline \multicolumn{4}{|l|}{ Age categories } \\
\hline $1-18$ & 286 & 3.5 & 5.8 \\
\hline $19-40$ & 533 & 6.6 & 10.8 \\
\hline $41-65$ & 2365 & 29.3 & 37.6 \\
\hline $66-79$ & 2665 & 33.0 & 29.0 \\
\hline 80 and older & 2222 & 27.5 & 16.8 \\
\hline \multicolumn{4}{|l|}{ Discharge status } \\
\hline Alive & 4039 & 50.0 & 95.3 \\
\hline Inpatient death & 4032 & 50.0 & 4.7 \\
\hline \multicolumn{4}{|l|}{ Gender } \\
\hline Male & 4155 & 51.5 & 50.0 \\
\hline Female & 3916 & 48.5 & 50.0 \\
\hline \multicolumn{4}{|l|}{ Patient admissions } \\
\hline University hospital & 1593 & 19.7 & 13.9 \\
\hline Tertiary teaching & 2843 & 35.2 & 44.1 \\
\hline General & 3635 & 45.0 & 41.9 \\
\hline $\begin{array}{l}\text { Length of hospital stay, } \\
\text { days (median/SD) }\end{array}$ & & & $6.5(4.0 / 12.1)$ \\
\hline \multicolumn{4}{|l|}{ Urgent admission } \\
\hline No & 2496 & 30.9 & 45.6 \\
\hline Yes & 5575 & 69.1 & 54.4 \\
\hline \multicolumn{4}{|l|}{$\begin{array}{l}\text { Department to which } \\
\text { patient was admitted }\end{array}$} \\
\hline Cardiology & 814 & 10.1 & 11.1 \\
\hline Surgery & 1410 & 17.5 & 21.7 \\
\hline Geriatrics & 163 & 2.0 & 1.1 \\
\hline Coronary Care Unit & 286 & 3.5 & 3.3 \\
\hline Intensive Care & 543 & 6.7 & 1.9 \\
\hline Paediatrics & 172 & 21.3 & 3.4 \\
\hline Internal medicine & 1720 & 2.1 & 16.2 \\
\hline Orthopaedics & 510 & 2.2 & 11.1 \\
\hline Neurology & 695 & 9.9 & 7.2 \\
\hline Pulmonology & 802 & 8.6 & 6.5 \\
\hline Ear, nose, and throat & 178 & 6.3 & 3.7 \\
\hline Urology & 251 & 3.1 & $5.0^{*}$ \\
\hline Other & 527 & 6.5 & $7.8 *$ \\
\hline
\end{tabular}

*Weighted for overrepresentation of deceased patients and hospital type. 
Damen, N.L., Baines, R., Wagner, C., Langelaan, M. Medication-related adverse events during hospitalization: a retrospective patient record review study in the Netherlands. British Journal of Clinical Pharmacology: 2016

Table 2. Patient and hospital characteristics of medication-related adverse events

\begin{tabular}{|c|c|c|}
\hline & $\begin{array}{c}\text { MRAEs } \\
(n=204) * \\
n \text { (column } \%, \\
\text { weighted) }\end{array}$ & $\begin{array}{l}\text { Preventable MRAEs } \\
\qquad(n=53)^{*} \\
n \text { (row } \%,^{\text {weighted) }}{ }^{1+}\end{array}$ \\
\hline \multicolumn{3}{|l|}{ Age categories } \\
\hline $1-18$ & $5(4.2)$ & $0(0.0)$ \\
\hline $19-40$ & $9(4.0)$ & $1(22.6)$ \\
\hline $41-65$ & $47(25.1)$ & $7(17.4)$ \\
\hline $66-79$ & $88(41.3)$ & $24(17.9)$ \\
\hline 80 and older & $55(25.5)$ & $21(22.7)$ \\
\hline \multicolumn{3}{|l|}{ Discharge status } \\
\hline Alive & $67(90.9)$ & $11(17.2)$ \\
\hline Inpatient death & $137(9.1)$ & $42(30.7)$ \\
\hline \multicolumn{3}{|l|}{ Gender } \\
\hline Male & $104(46.8)$ & $26(18.1)$ \\
\hline Female & $100(53.2)$ & $27(18.7)$ \\
\hline \multicolumn{3}{|l|}{ Patient admissions } \\
\hline University hospital & $41(14.5)$ & $8(14.5)$ \\
\hline Tertiary teaching & $57(36.9)$ & $13(21.2)$ \\
\hline General & $106(48.7)$ & $32(17.5)$ \\
\hline \multicolumn{3}{|l|}{ Urgent admission } \\
\hline No & $44(26.1)$ & $8(14.0)$ \\
\hline Yes & $160(73.9)$ & $45(20.0)$ \\
\hline \multicolumn{3}{|c|}{$\begin{array}{l}\text { Department to which patient } \\
\text { was admitted }\end{array}$} \\
\hline Cardiology & $19(8.5)$ & $9(7.2)$ \\
\hline Surgery & $11(2.2)$ & $3(9.0)$ \\
\hline Geriatrics & $5(1.4)$ & $2(9.6)$ \\
\hline Coronary Care Unit & $5(3.1)$ & $3(7.6)$ \\
\hline Intensive Care & $15(5.8)$ & $4(29.2)$ \\
\hline Internal medicine & $75(33.4)$ & $13(6.9)$ \\
\hline Paediatrics & $2(2.0)$ & - \\
\hline Ear, nose, and throat & $2(1.1)$ & - \\
\hline Pulmonology & $28(15.1)$ & $8(25.9)$ \\
\hline Neurology & $15(6.9)$ & $4(34.1)$ \\
\hline Orthopaedics & $8(5.5)$ & $2(29.0)$ \\
\hline Urology & $6(7.1)$ & $3(50.1)$ \\
\hline Other & $13(7.8)$ & $2(23.1)$ \\
\hline
\end{tabular}

MRAE, medication-related adverse event.

*MRAEs - admission level.

${ }^{\dagger}$ Weighted for overrepresentation of deceased patients and hospital type.

${ }^{+}$No preventability was shown if numbers of MRAEs were smaller than 5 . 
Damen, N.L., Baines, R., Wagner, C., Langelaan, M. Medication-related adverse events during hospitalization: a retrospective patient record review study in the Netherlands. British Journal of Clinical Pharmacology: 2016

Table 3. Drug type of medication-related adverse events

\begin{tabular}{lcc}
\hline & $\begin{array}{c}\text { MRAEs } \\
(n=218)^{*}\end{array}$ & $\begin{array}{c}\text { Preventable MRAEs } \\
(n=55)^{*}\end{array}$ \\
& $n$ (column \%, weighted) $^{\dagger}$ & $n$ (row \%, weighted) $^{\dagger \neq}$ \\
\hline Antiasthmatic & $1(0.0)$ & - \\
Antibiotic & $22(13.6)$ & $3(11.2)$ \\
Anticoagulant & $43(17.1)$ & $17(42.5)$ \\
Antidepressant & $1(1.8)$ & - \\
Antiepileptic & $2(1.1)$ & - \\
Antihypertensive & $4(2.9)$ & $1(1.6)$ \\
Antiplatelet & $7(6.3)$ & - \\
Antipsychotic & $2(0.1)$ & $3(0.7)$ \\
Chemotherapy & $58(22.0)$ & $5(4.4)$ \\
Cardiovascular & $11(6.9)$ & $0(0.0)$ \\
Diuretic & $5(3.1)$ & $7(34.8)$ \\
Insulin/Oral & $12(5.0)$ & - \\
diabetic & $1(0.0)$ & $2(5.3)$ \\
Potassium & $9(3.0)$ & - \\
Morphine/Opioid & $1(0.0)$ & $4(15.5)$ \\
NSAID & $9(1.4)$ & $7(27.8)$ \\
Sedative & $30(15.5)$ & $55(18.4)$ \\
Other & $218(100)$ & \\
Total & & \\
\hline
\end{tabular}

MRAE, medication-related adverse event; NSAID, non-steroidal anti-inflammatory drug.

*MRAEs - adverse event level.

${ }^{\dagger}$ Weighted for overrepresentation of deceased patients and hospital type.

${ }^{7}$ No preventability was shown if numbers of MRAEs were smaller than 5 . 
Damen, N.L., Baines, R., Wagner, C., Langelaan, M. Medication-related adverse events during hospitalization: a retrospective patient record review study in the Netherlands. British Journal of Clinical Pharmacology: 2016

Table 4. Patient and hospital characteristics of anticoagulant-related adverse events

\begin{tabular}{|c|c|c|}
\hline & $\begin{array}{l}\text { Anticoagulant- } \\
\text { related } \\
\text { AE }(n=41)^{*} \\
n \text { (column } \%,^{\text {weighted) }}{ }^{\dagger}\end{array}$ & $\begin{array}{c}\text { Preventable } \\
\text { anticoagulant-related } \\
\mathrm{AE}(n=17)^{*} \\
n \text { (row } \%, \\
\text { weighted) }\end{array}$ \\
\hline \multicolumn{3}{|l|}{ Age categories } \\
\hline $1-18$ & $0(0.0)$ & - \\
\hline $19-40$ & $1(0.3)$ & - \\
\hline $41-65$ & $5(14.0)$ & $2(60.8)$ \\
\hline $66-79$ & $17(33.0)$ & $7(39.0)$ \\
\hline 80 and older & $18(52.7)$ & $8(40.6)$ \\
\hline \multicolumn{3}{|l|}{ Gender } \\
\hline Male & $22(38.6)$ & $10(57.0)$ \\
\hline Female & $19(61.4)$ & 7 (33.8) \\
\hline \multicolumn{3}{|l|}{ Discharge status } \\
\hline Alive & $11(89.3)$ & $4(42.6)$ \\
\hline Inpatient death & $30(10.7)$ & $13(44.1)$ \\
\hline \multicolumn{3}{|l|}{ Urgent admission } \\
\hline No & $10(15.9)$ & $3(6.5)$ \\
\hline Yes & $31(84.1)$ & $14(49.6)$ \\
\hline \multicolumn{3}{|l|}{ Patient admissions } \\
\hline University hospital & $6(10.7)$ & $0(0.0)$ \\
\hline Tertiary teaching & $9(51.2)$ & $4(59.7)$ \\
\hline General & $26(38.2)$ & $13(32.1)$ \\
\hline \multicolumn{3}{|c|}{$\begin{array}{l}\text { Department to which patient } \\
\text { was admitted }\end{array}$} \\
\hline Cardiology & $6(2.1)$ & $4(65.8)$ \\
\hline Surgery & $4(1.4)$ & - \\
\hline Geriatrics & $1(0.4)$ & - \\
\hline Coronary Care Unit & $3(16.1)$ & - \\
\hline Intensive Care & $1(0.3)$ & - \\
\hline Internal medicine & $13(25.9)$ & $5(37.0)$ \\
\hline Paediatrics & $0(0.0)$ & - \\
\hline Ear, nose, and throat & $1(0.3)$ & - \\
\hline Pulmonology & $3(19.6)$ & - \\
\hline Neurology & $3(1.2)$ & - \\
\hline Orthopaedics & $2(0.7)$ & - \\
\hline Urology & $4(32.1)$ & - \\
\hline Other & $0(0.0)$ & - \\
\hline
\end{tabular}

$\mathrm{AE}$, adverse event.

*MRAEs - admission level.

${ }^{\dagger}$ Weighted for overrepresentation of deceased patients and hospital type.

${ }^{+}$No preventability was shown if numbers of MRAEs were smaller than 5 . 
Damen, N.L., Baines, R., Wagner, C., Langelaan, M. Medication-related adverse events during hospitalization: a retrospective patient record review study in the Netherlands. British Journal of Clinical Pharmacology: 2016

Table 5. Factors and consequences of anticoagulant-related adverse events

\begin{tabular}{|c|c|c|}
\hline & $\begin{array}{l}\text { Anticoagulant- } \\
\text { related } \\
\text { AEs }(n=43)^{*} \\
n \text { (column } \%, \\
\text { weighted) }\end{array}$ & $\begin{array}{c}\text { Preventable } \\
\text { anticoagulant-related } \\
\text { AEs }(n=17)^{*} \\
n \text { (row \%, } \\
\text { weighted) }\end{array}$ \\
\hline \multicolumn{3}{|l|}{ Prescribing factors } \\
\hline Administrative/Procedure & $0(0.0)$ & - \\
\hline Dosage & $14(46.9)$ & $7(66.3)$ \\
\hline Therapeutic & $6(10.1)$ & $4(90.6)$ \\
\hline Delivery & $0(0.0)$ & - \\
\hline Administering & $0(0.0)$ & - \\
\hline Other & $22(20.0)$ & $11(20.0)$ \\
\hline \multicolumn{3}{|l|}{ Type of adverse event } \\
\hline Shock & $1(0.4)$ & - \\
\hline Heart failure & $1(0.4)$ & - \\
\hline Pulmonary embolism & $2(0.7)$ & - \\
\hline Renal insufficiency & $1(6.8)$ & - \\
\hline Other renal failure & $1(0.4)$ & - \\
\hline Intra-cerebral haemorrhage & $8(25.5)$ & $3(38.6)$ \\
\hline Thromboembolism & $1(0.4)$ & - \\
\hline Haematoma & $5(39.0)$ & $1(31.0)$ \\
\hline Gastro-intestinal bleeding & $9(12.6)$ & $4(14.2)$ \\
\hline Cerebrovascular accident & $7(3.0)$ & $0(0.0)$ \\
\hline $\begin{array}{l}\text { Catheter-related blood } \\
\text { infection }\end{array}$ & $1(0.3)$ & - \\
\hline Pulmonary infection & $1(0.4)$ & - \\
\hline Postsurgical haemonhage & $1(0.4)$ & - \\
\hline Other & $1(9.9)$ & - \\
\hline \multicolumn{3}{|l|}{ Consequences $^{5}$} \\
\hline Intervention & $26(80.2)$ & $10(40.3)$ \\
\hline $\begin{array}{l}\text { Impaiment at moment of } \\
\text { discharge }\end{array}$ & $1(4.9)$ & - \\
\hline Extended length of stay & $4(5.9)$ & - \\
\hline Readmission & $2(18.9)$ & - \\
\hline Death & $18(12.1)$ & $4(11.3)$ \\
\hline Outpatient visit & $1(10.8)$ & - \\
\hline Other & $2(11.1)$ & - \\
\hline
\end{tabular}

AE, adverse event.

*MRAEs - adverse event level.

${ }^{\dagger}$ Weighted for overrepresentation of deceased patients and hospital type.

${ }^{+}$No preventability was shown if numbers of MRAEs were smaller than 5 .

${ }^{5}$ More than one answer was possible. Therefore, the total percentage sums up to more than 100. 